•保护论坛・

\title{
中国生物多样性保护的变革性转变及路径
}

杨 锐 ${ }^{*}$ 彭钦一曹越钟乐侯姝或赵智聪黄 澄

(清华大学建筑学院/清华大学国家公园研究院, 北京 100084)

\begin{abstract}
摘要: 全球正在经历第六次物种大灭绝。为了应对生物多样性丧失速率日益加快的严峻挑战, 《生物多样性公约》 第十届缔约方大会通过了《生物多样性战略计划》(2011-2020年)及20项爱知生物多样性目标。然而, 2019年IPBES 全球评估报告表明, 大部分爱知目标可能无法在2020年实现, 因此, 自然保护需要变革性转变。中国虽然在生物多 样性保护方面取得了巨大成就，提出了系统完整的生态文明制度及建立“以国家公园为主体的自然保护地体系”的 目标, 并通过绿盾行动和环保督察提升了生物多样性保护的重要性, 陆地自然保护地覆盖率也已达到 $18 \%$, 但仍 未有效遏制生物多样性下降的趋势, 物种濒危程度持续加剧。尽管生态文明一系列改革已经做出了变革性转变, 中央层面大力推行生物多样性“主流化”的相关政策，通过机构改革初步解决了自然保护地“九龙治水”的问题，在 国土空间规划和生态保护红线划定中强调了生物多样性保护的重要性, 但是, 生物多样性保护仍然缺乏系统性的 解决策略, 需要在不同层面进一步落实 “主流化”, 建立完整的法律体系和统一规范高效的保护机制, 保障保护资 金, 明确生物多样性在生产、生活空间中的地位, 打通自然保护成果与经济利益的转化渠道。因此, 中国的生物多 样性保护应当借助生态文明建设的历史性机遇, 在保护意识、空间布局和保护行动 3 个方面充分实现变革性的转 变, 借助五位一体总体布局, 采用系统化的解决方法, 进一步整合法律、行政、市场、技术和社会等五方面力量, 提 出具体的实现路径, 实现保护意识主流化、保护利用统筹化和保护行动全民化等三方面变革性的转变, 形成高效 一体化的机制，以实现“人与自然和谐相处”的生物多样性保护理想状态。
\end{abstract}

关键词: 变革性转变; 生物多样性“主流化”; 保护利用统筹; 国土空间规划; 自然保护地

\section{Transformative changes and paths toward biodiversity conservation in China}

\author{
Rui Yang*, Qinyi Peng, Yue Cao, Le Zhong, Shuyu Hou, Zhicong Zhao, Cheng Huang \\ School of Architecture, Tsinghua University/ Institute for National Parks, Tsinghua University, Beijing 100084
}

\begin{abstract}
Earth is experiencing its sixth mass extinction, and in response to the severity of accelerated biodiversity loss, the 10th meeting of the Conference of the Parties to the Convention on Biological Diversity (CBD) adopted the Strategic Plan for Biodiversity 2011-2020, including Aichi Biodiversity Targets. However, the IPBES global assessment showed that most of the Aichi Biodiversity Targets for 2020 will possibly be missed, because of which the IPBES called for transformative changes in nature conservation in its global assessment report. China has made significant progress in biodiversity conservation, put forward with completed eco-civilization system, try to develop a protected area system, stress the importance of biodiversity conservation by inspection and "Green Shield" action. In addition, up to 18\% of territory has been designated as protected area. However, biodiversity is still declining at an accelerated rate, more species are threatened. Although a series of reforms to eco-civilization has started the transformative changes, such as mainstreaming biodiversity in central government, managing all the protected areas in one department, emphasizing the importance of biodiversity in national spatial planning and China Ecological Conservation Red Line (ECRL) designation, systematic strategies and actions are still in need for biodiversity conservation. It is important to further implement "mainstreaming" at different levels, establish a systematic legal system and effective conservation mechanism, guarantee enough funds, clarify the status of biodiversity in
\end{abstract}

收稿日期: 2019-07-04; 接受日期: 2019-09-25

基金项目：国家社会科学基金重大项目(14ZDB142)、国家自然科学基金(51708323)和国家社会科学基金(18BGL178)

* 通讯作者 Author for correspondence. E-mail: yrui@mail.tsinghua.edu.cn 
production and living space, and make ecosystem service possible to become economic benefits. Therefore, it is necessary for China to achieve transformative changes in terms of conservation awareness, spatial planning, and conservation actions by promoting balanced economic, political, cultural, social, and ecological progress. It is possible to mainstream conservation awareness, coordinate between conservation and utilization, and promote citizen-based conservation actions if China combines the forces of law, governance, market, technology, and society. This approach world form an efficient and integrated mechanism to achieve the ideal state of biodiversity conservation, "living in harmony with nature".

Key words: transformative changes; mainstreaming biodiversity; coordination between conservation and utilization; national spatial planning; protected areas

目前, 全球正在经历第六次物种大灭绝(Barnosky et al, 2011; Pimm et al, 2014; Ceballos et al, 2015), 而爱知生物多样性目标的实现状况并不理 想, 全球的生物多样性保护需要变革性的转变 (IPBES, 2019)。中国同样面临着严峻的生物多样性 保护形势, 在这种情况下, 2020年《生物多样性公 约》(CBD)第15届缔约方大会(COP15)将在中国召开 (邹玥屿等, 2017; 刘文静等, 2018), 中国应该提出 什么样的2020后全球生物多样性框架? 中国生物 多样性保护应当何去何从? 本文希望通过对全球 爱知目标的回顾与评价, 总结爱知目标的不足, 并 对中国生物多样性保护的问题进行深入分析, 提出 中国生物多样性保护变革性转变的方向与实现路 径。全文将围绕以下3个问题展开: (1)为什么中国的 生物多样性保护需要变革性转变? (2)什么是中国生 物多样性保护的变革性转变? 以及(3)如何实现中 国生物多样性保护的变革性转变?

\section{为什么中国的生物多样性保护需要变} 转变?

\section{1 全球生物多样性保护需要变革性转变}

为了应对生物多样性日益丧失的严峻挑战, 第 十届CBD缔约方大会通过了《生物多样性战略计 划》(2011-2020年), 确立了2020年应当实现的5项战 略目标, 并细分为 20 项具体的爱知目标。其中, 战 略目标A希望通过生物多样性保护“主流化”来应对 生物多样性丧失的根本原因; 战略目标B关注减少 生态压力; 战略目标 $C$ 关注保护措施与预期成效; 战略目标 $\mathrm{D}$ 关注生态惠益的共享; 战略目标 $\mathrm{E}$ 则为 前四个战略提供保障。在爱知目标的激励下, 全球 的生物多样性保护事业已取得了较大进展, 截至 2018年7月, 全球共有238,563处自然保护地, 占全
球陆地和内陆水域面积的 $14.9 \%$, 占全球海洋面积 的 $7.3 \%$, 有希望实现爱知目标 $11^{\circledR}$ 的覆盖率要求 (https://livereport.protectedplanet.net/pdf/Protected_Pl anet_Report_2018.pdf)。然而爱知目标整体完成情况 不佳, 在20项目标中, 只有4项目标进展良好, 7项 目标进展缓慢, 6项目标进展较差。总体而言, 全球 范围内的自然系统正在持续退化, 而导致自然退化 的直接和间接驱动因素的影响仍在扩大。如果按照 现有的保护模式, 生物多样性保护和可持续发展的 目标将无法实现, 生物多样性保护迫切需要与其他 社会目标协同努力, 以促进变革性的转变(IPBES, 2019)。

IPBES (The Intergovernmental Science-Policy Platform on Biodiversity and Ecosystem Services, 生 物多样性和生态系统服务政府间科学-政策平台)的 全球评估表明，虽然爱知目标提出生物多样性“主 流化”、减缓生态压力和有关自然保护地质量的目 标, 但依然无法解决自然保护地内外的问题。第一, 爱知目标并未对生物多样性丧失的根源——社会 经济的运行机制提出有针对性的目标和有效措施 (Buscher et al, 2017; IPBES, 2019), 缺乏推动生物多 样性“主流化”的基础。全球评估表明，各国政府未 能有效控制生态压力, 也未能营造有利于生物多样 性保护的社会和政策环境(IPBES, 2019), 生物多样 性保护未能成为主流思想, 来自自然保护地之外的 生态压力日益严峻。第二, 爱知目标未形成自然保 护和生态惠益分享的良性循环机制，对自下而上的 保护力量的激励不足(IPBES, 2019)。第三, 爱知目

(1) 爱知目标 11: 到 2020 年, 至少有 $17 \%$ 的陆地和内陆水域以及 $10 \%$ 的 海岸和海洋区域, 尤其是对于生物多样性和生态系统服务具有特殊重 要性的区域, 通过建立有效而公平管理的、生态上有代表性和连通性好 的保护区系统和其他基于区域的有效保护措施而得到保护，并与更广 泛的陆地景观和海洋景观形成整体. 
标对自然保护地的质量缺乏相应的激励措施, 虽然 各国保护地覆盖率持续增长, 但是自然保护地连通 性不佳(Santini et al, 2016; Saura et al, 2017, 2018)、 受威胁物种的保护地覆盖率严重不足(Venter et al, 2014; Butchart et al, 2015; Jenkins \& Van Houtan, 2016)、自然保护地管理有效性不足(Watson et al, 2014; Di Minin \& Toivonen, 2015; Pringle, 2017)等 问题依然严重。第四，自然保护地覆盖率指标过低。 爱知目标11所规定的保护 $17 \%$ 的陆地和内陆水域以 及 $10 \%$ 的海岸和海洋区域的目标, 主要基于政治可 行性, 远不足以有效保护全球的生物多样性(Venter et al, 2014; Butchart et al, 2015; Larsen et al, 2015; O’leary et al, 2016), 需要基于科学研究为自然保护 地设置更高远的目标(曹越等, 2019)。

由于日益严峻的全球生物多样性保护形势, IPBES在全球评估报告中呼吁自然保护的变革性转 变, 并指出“若想要实现2030年或者更长期的自然 保护目标, 只能通过在经济、社会、政治和技术方 面实现变革性转变” (IPBES, 2019)。

\section{2 中国生物多样性保护需要变革性转变}

中国在生物多样性保护方面已取得一定成就。 在体制方面, 十八大以来, 中国生物多样性保护事 业进入了新的阶段。《生态文明体制改革总体方案》 明确提出了建立由自然资源资产产权制度、国土空 间开发保护制度、空间规划体系、资源总量管理和 全面节约制度、资源有偿使用和生态补偿制度、环 境治理体系、环境治理和生态保护市场体系、生态 文明绩效评价考核和责任追究制度构成的完整的 生态文明制度体系，其中新建制度22项、健全和完 善制度多达25项(王海芹和高世楫, 2016); 十九大 提出 “建立以国家公园为主体的自然保护地体系”, 十九大之后的机构改革为生物多样性保护打下了 良好的行政基础, 绿盾行动和环保督察进一步提升 了保护的重要性。在就地保护方面, 陆地自然保护 地覆盖率已达 $18 \%$, 各类生态保护区域(存在交叉重 叠)的总面积已经超过陆域面积的 50\% (杨锐和曹 越, 2018)。就爱知目标的完成情况而言, 根据CBD 官网对各国家的评估, 截至2019年, 中国已完成16 项爱知目标(https://chm.cbd.int/search/reporting-map? filter=AICHI-TARGET-20)。

然而, 《中国生物多样性保护战略与行动计划 (2010-2030年)》(http://www.mee.gov.cn/gkml/hbb/ bwj/201009/t20100921_194841_wap.shtml) 提出的 “到2020年，努力使生物多样性的丧失与流失得到 基本控制”的中期目标完成情况不容乐观。相关研 究表明, 生物多样性下降的趋势并未得到有效遏制 (徐海根等, 2016), 部分生物多样性热点区域尚未得 到有效保护, 生态系统功能仍在持续退化, 物种濒 危程度不断加剧(http://hinature.cn:8012/Upload/ files/2017/11/7/20171107144049281.pdf), 未形成中 期目标所希冀的合理完整的自然保护地空间网络 (闻丞等, 2015)。总之, 中国的生物多样性保护仍存在 以下问题: (1)生物多样性保护“主流化”程度不足，体 制机制不健全(王伟等, 2016; 彭琳等, 2017), 自然保 护地管理水平较低(马克平, 2011), 科研能力有待加 强。(2)自然保护地内外未形成保护的空间合力。一方 面，自然保护地空间布局不合理，另一方面，仅依 靠自然保护地无法应对日益增大的生态压力(蔵春 金等, 2016)。(3)社会力量的参与不足, 生物多样性 保护缺乏公众参与的渠道(张婧雅和张玉钧, 2017)。

中国生物多样性保护的问题是系统性的问题, 源于认识、立法、体制、资金、技术、能力和外部 环境等方面的“七个不到位” (杨锐, 2003)。在认识方 面，十八大以来，尽管中央已经做出了变革性的转 变, 但是地方政府、企业和普通民众的认识转变滞 后，并未在思想认识层面真正实现生物多样性保护 的“主流化”; 在立法方面，缺少生物多样性保护方 面的基本法, 现有的自然保护相关立法质量也较低, 远远跟不上生物多样性保护方面的现实需求; 在行 政体制方面，中央通过机构改革初步解决了自然保 护地“九龙治水”的问题，实现了变革性转变，然而 统一规范高效的生物多样性保护体制在不同层面 的落实仍然有相当长的路要走; 在资金方面, 各级 财政投入生物多样性保护的资金总量不足，缺乏统 筹，资金利用效率偏低; 在技术方面，生物多样性 保护在生产和生活空间中的地位尚未明确, 科研工 作和监测的薄弱仍是严重问题; 在生物多样性保护 的外部环境方面, 缺乏保护成果与经济利益的转化 渠道，难以调动公众的保护积极性。

系统性的问题需要系统性的解决策略。虽然生 态文明制度体系提供了一个较为清晰的框架，但并 未针对生物多样性保护领域的“主流化”问题、空间 
问题和社会参与问题提出变革性、系统性的具体路 径。因此, 若想要实现《中国生物多样性保护战略 与行动计划(2010-2030年)》提出的“到2030年, 使生 物多样性得到切实保护”的目标, 必须在生态文明制 度框架内, 整合法律、行政、市场、技术、社会等方 面的力量, 通过一系列变革性的转变来提升全体国 民的生物多样性保护意识, 统筹自然保护地与外部 空间, 凝聚自上而下和自下而上的保护力量, 才能 将生态文明建设的一系列努力转化为真切实在的 生物多样性保护成效。

\section{2 什么是中国生物多样性保护的变革性转变}

中国的生物多样性保护应当进行什么样的变 革性转变? 在回答这个问题之前, 应先回答“什么 是中国生物多样性保护的理想状态”这一问题。美 好可行的愿景能够为生物多样性保护提供持续的 动力和变革性转变的方向, 我们认为中国的生物多 样性保护也应当把“人与自然和谐相处”作为理想状 态，这既顺应CBD提出的“2050愿景”，也顺应了“天 人合一”的中国传统智慧，响应十九大将“坚持人与 自然和谐共生”作为新时代中国特色社会主义的基 本方略之一的时代号召。具体而言, 应当具有如下 特征: (1)生态保护和绿色发展良性互动, 国土空间 的每一寸土地都兼顾保护与发展的目标(杨锐和曹 越, 2018); (2)人居环境和自然保护地的阴阳互补, 对自然保护地、其他保护性用地 (OECM, other effective area-based conservation measures)、其他国 土空间进行整体保护, 实现系统化的生物多样性保 护与人居环境建设; (3)生物多样性保护和社会公平 相互促进，自然保护有效促进公益(国民游憩机会) 与地域公平、代际公平 (杨锐, 2014); (4)美丽国土和 美丽心灵交相辉映, 人类从自然中获得精神滋养, 促进精神境界的提升。

为了实现生物多样性保护的理想状态，中国需 要在保护意识、空间布局和保护行动等3个方面进 行变革性的转变, 以实现保护意识的主流化、保护 利用的统筹化和保护行动的全民化。

(1)保护意识主流化是生物多样性保护的认识 基础。“两山论”的提出正在逐渐转变保护与发展对 立的认识, 然而, 仅在政治层面强调“绿水青山”的 重要性并不足够, 需要在社会、经济、政策、文化
等各方面进一步强调生物多样性保护的重要性, 并 通过系统性的自然教育，促进价值观从“人类中心 主义”向“生态整体主义”转变, 让每一个国民都认 识到生物多样性保护与自身息息相关。

(2)保护利用统筹化是减缓生态压力的根本措 施。国土空间规划体系的建立正在提升生物多样性 保护的重要性，逐渐协调保护和利用的关系。然而， 局限于自然保护地的保护方式无法实现有效的生 物多样性保护, 首先应当建立全域性的生物多样性 保护-绿色发展政策框架; 其次, 在国土空间规划 中, 将生物多样性保护的理念和目标全面融入生产 空间、生活空间和生态空间, 使国土空间的每一寸土 地兼具保护和发展的功能; 第三, 科学制定自然保 护地覆盖率目标, 补充保护空缺, 将孤立的保护岛屿 转变为完整、连通的生物多样性保护网络和社会-生 态景观，协调城镇体系与自然保护地体系的关系。

(3)保护行动全民化是生物多样性保护最有效 的手段。机构改革、绿盾行动和环保督察等都对生 物多样性保护产生了积极的影响, 然而, 这些行动 的参与者仍是少数群体, 需要自上而下的指令来监 督落实。在此基础上, 应将生物多样性保护由少数 人的工作扩展为全社会参与的事业, 把生物多样性 保护的行为融入生产生活的方方面面; 更重要的是, 打通保护成果与其他利益的转化渠道, 形成生物多 样性保护行为与利益的良性循环, 调动自下而上的 保护热情。

生物多样性保护是一项系统工程, 为了实现保 护意识主流化、保护利用统筹化和保护行动全民化, 应当采用系统化的解决方法, 通过法律、行政、市 场、技术、社会等五方面的具体措施, 全方位地促 进中国生物多样性保护的变革性转变。

\section{如何实现中国生物多样性保护的变革性车}

中国具有极其丰富的生物多样性, 也是世界 “巨型荒野国家” (mega-wilderness nations)之一 (Watson et al, 2018; Cao et al, 2019), 并且正处于生 态文明建设的历史机遇期。如何借助中国生物多样 性保护的优势和机遇, 实现生物多样性保护的变革 性转变? 我们提出了五个方面的12条路径, 通过法 律、行政、市场和社会方面的路径, 将生物多样性 保护真正与每个公民的切身利益挂钩, 实现保护意 识主流化; 通过技术和市场方面的路径, 统筹国土 
空间的保护和利用，在空间布局方面实现保护利用 统筹化; 通过行政和社会方面的路径, 促进领导干 部和普通群众积极参与生物多样性保护事业, 实现 保护全民化, 最终形成高效一体化的生物多样性保 护机制，实现“人与自然和谐相处”的理想状态(图 1)。在法律方面, 完善生物多样性保护的系统性法 律框架, 提供生物多样性保护事业持续发展的根本 保障; 在行政方面, 完善生物多样性保护的体制机 制，将生物多样性保护纳入领导干部的绩效考核中， 提升生物多样性保护的地位; 在技术方面, 基于生 物多样性保护进行国土空间规划和空间用途管制, 统筹自然保护地与其他各类国土空间, 并建立科学 的生物多样性保护监测体系, 保证保护的质量; 在 市场方面, 建立自然保护地指标和生态系统服务的 交易市场，构建“绿水青山”向“金山银山”的转化渠 道, 激发自上而下与自下而上的保护热情; 在社会 方面, 通过持续的自然教育, 将社会各方力量纳入 生物多样性保护行动中。

\section{1 法律路径}

完善生物多样性保护的系统性法律框架。法律 体系是生物多样性保护事业持续发展的根本保障。 建议将“自然保护”理念全面融入法律体系，并建立 系统性强的生物多样性法律体系; 进一步建立“以 国家公园为主体的自然保护地体系”法律框架，形 成以《自然保护地法》为根基, 各类自然保护地的 国务院条例为中间层，各个国家公园管理实施细则 为底层的“ $1+\mathrm{N}+\mathrm{X}$ ”三层金字塔结构，其中位于最 顶层的“ 1 ”是指《自然保护地法》，它是整个法律框 架的根基; 中间层“N”指N项国务院条例，有几类自 然保护地就设置几个条例，最底层的“ $X$ ” 是指根据 《国家公园管理条例》，按照“一园一法”为每个个 体国家公园制定的管理实施细则(杨锐等, 2019)。

\section{2 行政路径}

\subsection{1 建立健全生物多样性保护的绩效考核制度}

绩效考核是领导干部的“指挥棒”。《生态文明体 制改革总体方案》提出建立绿色发展指标体系, 实

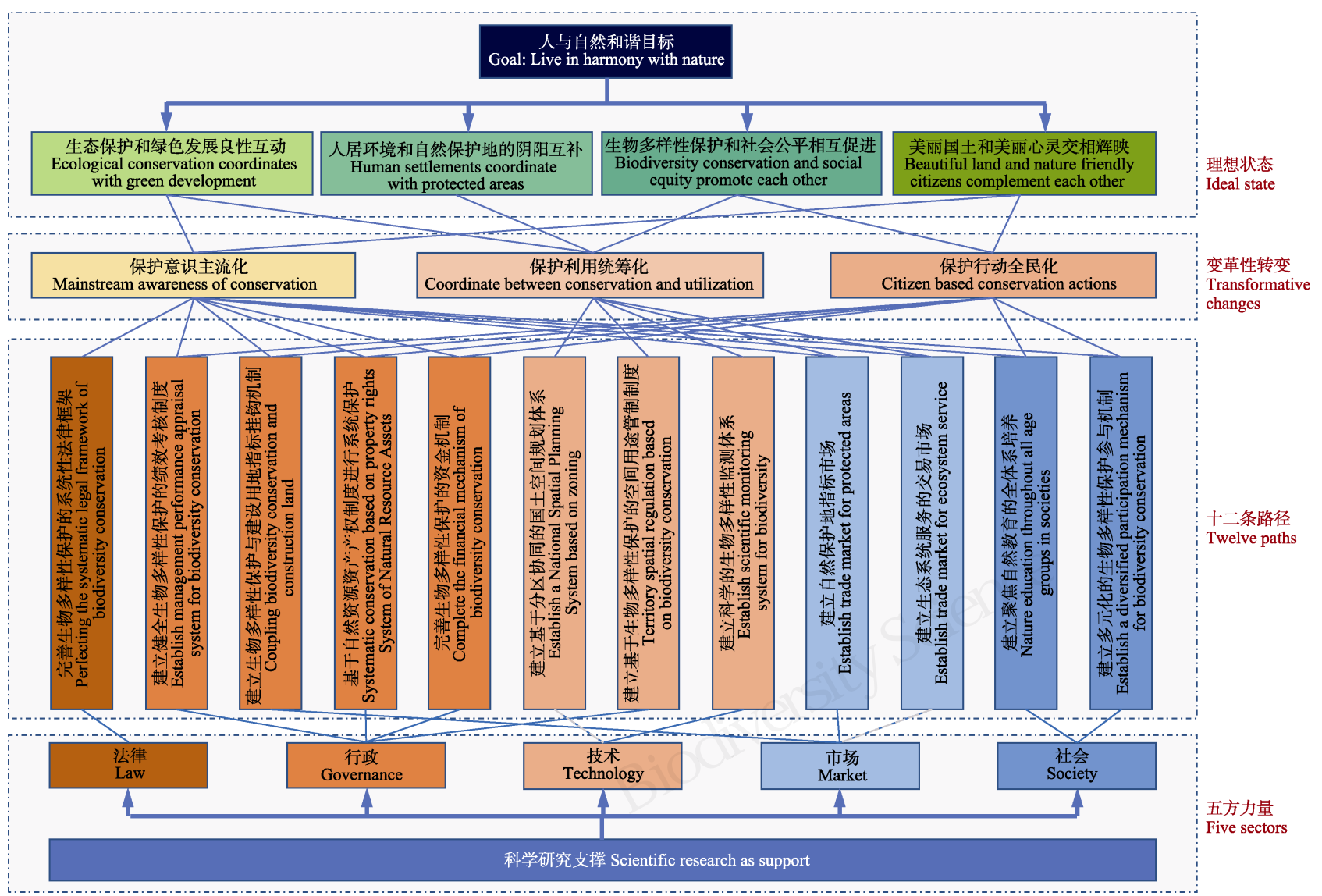

图1 中国生物多样性保护变革性转变的实现路径

Fig. 1 Paths toward transformative changes of biodiversity conservation in China 
行差异化绩效评价考核, 但并未出台具体的指标体 系和考核办法。建议将自然保护成效纳入领导干部 的绩效考核中, 将生物多样性作为重要的评价指标, 进一步推动生物多样性保护在政府部门的“主流化” 进程, 其中, 自然保护地覆盖率超过 30\%的区县, 应以保护成效为考核重点。

首先，根据不同区域的自然资源价值制定相应 的生物多样性保护目标。其次, 探索建立科学合理 的保护成效指标及评价体系, 将环境治理、生物多 样性、生态足迹、资源承载力状况、自然保护地网 络完整性等方面的指标纳入其中, 对现有的生态文 明建设绩效评价考核和责任追究指标进行补充和 完善。最后, 完善生物多样性保护的责任追究制度, 对保护成效实行领导干部离任审计和终身问责制。

\subsection{2 建立生物多样性保护与建设用地指标挂钩 机制}

新增建设用地指标是城镇建设和经济发展的 重要因素(李旺君和王雷, 2009)。建议将生物多样性 保护目标的完成情况纳入新增建设用地的重要测 算指标中, 未完成保护目标的省份, 按照一定比例 核减新增建设用地计划指标, 从而推动自然保护地 和城镇体系协调发展。

\subsection{3 基于自然资源资产产权制度进行系统保护}

山水林田湖草是生命共同体, 应进行整体、系 统的保护。建议首先加快生物多样性保护空缺区域 的自然资源资产的确权登记, 在此基础上, 基于保 护空缺区域的生态系统状况, 因地制宜, 统筹布局 社区保护地、社会公益保护地、少数民族地区的神 山圣湖等不同的保护地类型, 丰富自然保护地的保 护措施与治理模式, 提升自然保护地网络的覆盖率 和完整性。

\subsection{4 完善生物多样性保护的资金机制}

充足的资金是生物多样性保护的基础。建议进一 步加大生物多样性保护的财政投入, 提升其在国民 经济生产总值中所占的比例, 并完善跨地区的生态 补偿机制, 同时, 扩大融资渠道, 设立各级各类生 物多样性保护基金，鼓励企业、组织、个人积极向自 然保护地管理机构捐款; 在资金使用方面, 统筹使 用各类自然保护资金，确保资金科学、高效的使用。

\section{3 技术路径}

\subsection{1 建立基于分区协同的国土空间规划体系}

现有的国土空间规划体系通过科学布局生产、
生活和生态空间来协调开发和保护的关系，然而， 国土空间中的每一寸土地都同时具备保护与利用 的价值，即便是生产和生活空间，也应不同程度地 承担生物多样性保护的功能和义务。

建议在建立国土空间规划体系时，新设一类 “生态用地” (赵智聪和杨锐, 2019), 并将国土全域 视为广义的生态空间，通过分区制(zoning)在主体 功能区和 “三区三线”的基础上进行分级、分类的区 划细分，将国土空间纳入统一分区级别; 并根据保 护-发展连续谱，明确各个分区的保护与开发强度， 并构建由保护质量指标、发展控制指标、环境污染 指标和区域特色指标等组成的分区指标体系，借鉴 城市控规指标体系，确定各级分区的各类管制指标， 协调自然保护地与其他各类国土空间。在自然保护 地中，应强调保护质量和区域特色指标，在农业类 用地中, 强调环境污染指标; 在城乡建设各类用地 中, 强调发展控制、环境污染和以生物多样性为主 的保护质量指标。通过在国土的各个区域实现不同 程度的生物多样性保护，控制生态压力，实现自然 保护地内外的统筹。

\subsection{2 建立基于生物多样性保护的空间用途管制 制度}

空间用途管制是国土空间开发保护的主要手 段。建议尽快建立基于生物多样性保护的国土空间 用途管制制度，层层细化主体功能区、三区、三线 等不同空间区划的要求，并结合具体的用地类型， 进行差异化、精细化、科学化管理。

第一，建立刚弹结合的区划管制制度。从生物 多样性保护的角度制定由“三区三线”所形成的六类 空间的用途管制，确立生态保护红线、永久基本农 田、城镇开发边界的刚性管制措施，制定一般生态 空间、一般农业空间、一般城镇空间的弹性管制措 施及相互转化机制。

第二，建立差异管控的用地管制制度，在现有 的用地类型基础上，增设生态用地类型以满足生物 多样性保护需求，构建建设用地、农用地、未利用 地向生态用地转化的机制，对不同空间、不同类型 的土地实施差异化、有针对性的用途管制。

第三，将荒野作为一类特殊的管理政策单元进 行管理，建立中国荒野保护制度，抢救性保护原真 性最高的国家自然遗产(杨锐等, 2019)。建议将部分 自然保护地(特别是国家公园和自然保护区)的核心 
区域以荒野保护区(曹越和杨锐，2017)的形式进行 管理, 在国家公园等自然保护地内以尽可能大的面 积划定荒野保护区域; 对未被纳入自然保护地的荒 野地，通过制定科学的用途管制进行严格保护。

\subsection{3 建立科学的生物多样性保护监测体系}

科学的生物多样性保护监测体系为生物多样 性保护行动、保护成效评估、国土空间规划和用途 管制提供重要的数据支撑。建议在现有研究基础上, 结合生态系统服务和生物多样性评估的需求, 制定 保护成效的监测指标, 并加快研究制定能够快速、 准确、简洁地反映生物多样性保护质量的指标体系; 同时, 依托自然保护地体系完善监测网络, 实现监 测数据的系统化管理, 并建立数据共享机制, 提高 科研和管理评估的效率。

\section{4 市场路径}

\subsection{1建立自然保护地指标市场}

我国的自然保护地主要分布在胡焕庸线以西, 而绝大多数人口与经济活动分布在东南部。也就是 说, 相比于东部地区, 西部地区的人民承担了绝大 部分的生物多样性保护职责, 却没有享受足够多的 自然资源带来的利益。美国的“湿地银行”和澳大利 亚的“生物多样性信用”等做法, 利用市场手段很好 地协调了开发和利用的关系。类似的思路也可用于 调节保护和利用在空间上不平衡的问题。建议在科 学制定全国自然保护地覆盖率的基础上, 根据各省 所消耗的生态系统服务占比来确定各省应承担的 自然保护地面积指标。同时，以省级政府为交易主 体, 建立自然保护地面积指标流转市场, 已建自然 保护地面积多于面积指标的省份, 可以在流转市场 出售多余的自然保护地面积。一方面, 可以促进西 部地区“绿水青山”向“金山银山”的转化, 提升地方 政府的保护积极性; 另一方面激励各省采取可持续 的生产方式, 降低本省消耗的生态系统服务总量, 减少对环境的压力。

\subsection{2 建立生态系统服务的交易市场}

生态系统服务面临“有价无市”的困局, 无法实 现保护成果向资本收益的转化。建议由政府核算各 类开发行为所消耗的生态系统服务, 研究生物多样 性保护成果的量化指标, 建立生态系统服务有偿使 用机制, 开发商根据其开发行为, 向生态系统服务 供应商购买相应的生态系统服务; 同时，探索生态 系统服务与用能权、排污权、碳排放权等的市场换
算机制, 拓宽生物多样性保护成果的转化渠道, 更 好地实现保护行为与生态惠益的良性循环, 充分调 动自下而上的生物多样性保护积极性。

\section{5 社会路径}

\subsection{1 聚焦自然教育的全体系培养}

教育是生物多样性保护长期、有效的根本保 障。建议将自然教育纳入中小学和大学的通识教育 体系中, 并贯穿学前教育、基础教育、高等教育、 职业教育和成人教育等各阶段，在每一个国民身上 实现保护意识的“主流化”。

科学是生物多样性保护事业中不可或缺的要 素之一, 也是中国自然保护地的短板 (杨锐等, 2019)。建议尽快依托 “双一流”大学组建生态保护领 域的学科联盟，在学科配置上落实“五位一体”的总 体布局，培养生物多样性保护的高层次人才。

\subsection{2 建立多元化的生物多样性保护参与机制}

众人拾柴火焰高, 生物多样性保护事业不仅需 要政府和学术界的参与, 更需要个人、社区、企业、 非政府组织(NGO)的行动。能否调动广大人民群众 参与生物多样性保护事业, 是生物多样性保护乃至 生态文明建设成功与否的关键，建立多元化的参与 渠道则是群众参与保护的重要基础。

建议以社区为中心推广生物多样性保护行为, 广泛吸纳中小学老师、自然保护专业学生、环保主 义者等多元社会力量，营造社区参与保护的良好氛 围; 鼓励企业参与生物多样性保护，对自然友好型 企业进行绿色认证，引导消费者购买自然友好型企 业的产品, 推动企业减轻生态压力; 拓宽NGO与学 校、社区、政府在生物多样性保护方面的合作渠道, 鼓励 $\mathrm{NGO}$ 参与自然保护地管理、自然教育和相关 科研活动。

\section{结语}

我国正处在生态文明建设的关键时期，生物多 样性保护与生态文明建设息息相关，没有绿水青 山、缺乏生物多样性的文明无法称为生态文明。与 全球的生物多样性保护一样, 传统的保护措施已经 无法应对中国日益严峻的生物多样性保护形势, 我 们希望通过法律、行政、技术、市场和社会等 5 个方 面的12条路径，真正实现生物多样性保护的“主流 化”，并将自上而下与自下而上的保护力量相结合， 形成自然保护地内外的保护合力，提供“2020后”生 
物多样性保护的思路, 推动生物多样性保护这一伟 大事业的成功。

实现中国生物多样性保护的变革性转变是一 个漫长的过程, 需要更多科学研究作支撑。本文在 此抛砖引玉, 希望学术界共同努力, 共同促成生物 多样性保护的变革性转变, 实现人与自然和谐相处 的理想状态。

\section{参考文献}

Barnosky AD, Matzke N, Tomiya S, Wogan GOU, Swartz B, Quental TB, Marshall C, McGuire JL, Lindsey EL, Maguire KC, Mersey B, Ferrer EA (2011) Has the Earth's sixth mass extinction already arrived? Nature, 471, 51-57.

Buscher B, Fletcher R, Brockington D, Sandbrook C, Adams WM, Campbell L, Corson C, Dressler W, Duffy R, Gray N, Holmes G, Kelly A, Lunstrum E, Ramutsindela M, Shanker K (2017) Half-Earth or Whole Earth? Radical ideas for conservation, and their implications. Oryx, 51, 407-410.

Butchart SHM, Clarke M, Smith RJ, Sykes RE, Scharlemann JPW, Harfoot M, Buchanan GM, Angulo A, Balmford A, Bertzky B, Brooks TM, Carpenter KE, Comeros-Raynal MT, Cornell J, Ficetola GF, Fishpool LDC, Fuller RA, Geldmann J, Harwell H, Hilton-Taylor C, Hoffmann M, Joolia A, Joppa L, Kingston N, May I, Milam A, Polidoro B, Ralph G, Richman N, Rondinini C, Segan DB, Skolnik B, Spalding MD, Stuart SN, Symes A, Taylor J, Visconti P, Watson JEM, Wood L, Burgess ND (2015) Shortfalls and solutions for meeting national and global conservation area targets. Conservation Letters, 8, 329-337.

Cao Y, Carver S, Yang R (2019) Mapping wilderness in China: Comparing and integrating Boolean and WLC approaches. Landscape and Urban Planning, 192, 103636.

Cao Y, Yang R (2017) The research framework and key issues of Chinese wilderness studies. Chinese Landscape Architecture, 33(6), 10-15. (in Chinese with English abstract) [曹 越, 杨锐 (2017) 中国荒野研究框架与关键课题. 中国园 林, 33(6), 10-15.]

Cao Y, Yang R, Vance GM (2019) Nature needs half: A new vision for global protected areas. Landscape Architecture, 26(4), 39-44. (in Chinese with English abstract) [曹越, 杨 锐, 万斯.马丁 (2019) 自然需要一半: 全球自然保护地 新愿景. 风景园林, 26(4), 39-44.]

Ceballos G, Ehrlich PR, Barnosky AD, Garcia A, Pringle RM, Palmer TM (2015) Accelerated modern human-induced species losses: Entering the sixth mass extinction. Science Advances, 1, e1400253.

Di Minin E, Toivonen T (2015) Global protected area expansion: Creating more than paper parks. BioScience, 65, 637-638.

IPBES (2019) Summary for Policymakers of the Global Assessment Report on Biodiversity and Ecosystem Services of the
Intergovernmental Science-Policy Platform on Biodiversity and Ecosystem Services. IPBES Secretariat, Bonn, Germany.

Jenkins CN, Van Houtan KS (2016) Global and regional priorities for marine biodiversity protection. Biological Conservation, 204, 333-339.

Larsen FW, Turner WR, Mittermeier RA (2015) Will protection of $17 \%$ of land by 2020 be enough to safeguard biodiversity and critical ecosystem services? Oryx, 49, 74-79.

Li WJ, Wang L (2009) Analysis on the advantages and disadvantages of the pothook of the increase of city construction land and the decrease of rural residential land. Land and Resources Information, (4), 34-37. (in Chinese) [李旺君, 王雷 (2009) 城乡建设用地增减挂钩的利弊分析. 国土 资源情报, (4), 34-37.]

Liu WJ, Xu J, Geng YJ, Tian Y, Yin SL (2018) Progress in negotiations on the Post-2020 Global Biodiversity Framework and suggestions for Chinese government. Biodiversity Science, 26, 1358-1364. (in Chinese with English abstract) [刘文静, 徐靖, 耿宜佳, 田瑜, 银森录 (2018) “2020年 后全球生物多样性框架”的谈判进展以及对我国的建议. 生物多样性, 26, 1358-1364.]

Ma KP (2011) Strategic targets for biodiversity conservation in 2011-2020. Biodiversity Science, 19, 1-2. (in Chinese) [马 克平 (2011) 未来十年的生物多样性保护目标. 生物多 样性, 19, 1-2.]

O’Leary BC, Winther-Janson M, Bainbridge JM, Aitken J, Hawkins JP, Roberts CM (2016) Effective coverage targets for ocean protection. Conservation Letters, 9, 398-404.

Peng L, Zhao ZC, Yang R (2017) Analysis on the problems of protected area system in China and the countermeasure. Chinese Landscape Architecture, 33(4), 108-113. (in Chinese with English abstract) [彭琳, 赵智聪, 杨锐 (2017) 中 国自然保护地体制问题分析与应对. 中国园林，33(4), 108-113.]

Pimm SL, Jenkins CN, Abell R, Brooks TM, Gittleman JL, Joppa LN, Raven PH, Roberts CM, Sexton JO (2014) The biodiversity of species and their rates of extinction, distribution, and protection. Science, 344, 1246752.

Pringle RM (2017) Upgrading protected areas to conserve wild biodiversity. Nature, 546, 91-99.

Santini L, Saura S, Rondinini C (2016) Connectivity of the global network of protected areas. Diversity and Distributions, 22, 199-211.

Saura S, Bastin L, Battistella L, Mandrici A, Dubois G (2017) Protected areas in the world's ecoregions: How well connected are they? Ecological Indicators, 76, 144-158.

Saura S, Bertzky B, Bastin L, Battistella L, Mandrici A, Dubois G (2018) Protected area connectivity: Shortfalls in global targets and country-level priorities. Biological Conservation, 219, 53-67.

Venter O, Fuller RA, Segan DB, Carwardine J, Brooks T, Butchart SHM, Di Marco M, Iwamura T, Joseph L, O’Grady D, 
Possingham HP, Rondinini C, Smith RJ, Venter M, Watson JEM (2014) Targeting Global Protected Area Expansion for Imperiled Biodiversity. PLoS Biology, 12(6), e1001891.

Wang HQ, Gao SJ (2016) Germination, starting and policy evolution of green development in China: Observation of some stage characteristics. Reform, (3), 6-26. (in Chinese with English abstract) [王海芹, 高世楫 (2016) 我国绿色 发展萌芽、起步与政策演进: 若干阶段性特征观察. 改革, (3), 6-26.]

Wang W, Xin LJ, Du JH, Chen B, Liu FZ, Zhang LB, Li JS (2016) Evaluating conservation effectiveness of protected areas: Advances and new perspectives. Biodiversity Science, 24, 1177-1188. (in Chinese with English abstract) [王伟, 辛利娟, 杜金鸿, 陈冰, 刘方正, 张立博, 李俊生 (2016) 自然保护地保护成效评估: 进展与展望. 生物多样性, 24, 1177-1188.]

Watson JEM, Dudley N, Segan DB, Hockings M (2014) The performance and potential of protected areas. Nature, 515, 67-73.

Watson JEM, Venter O, Lee J, Jones KR, Robinson JG, Possingham HP, Allan JR (2018) Protect the last of the wild. Nature, 563, 27-30.

Wen C, Gu L, Wang H, Lü Z, Hu RC (2015) GAP analysis on national nature reserves in China based on the distribution of endangered species. Biodiversity Science, 23, 591-600. (in Chinese with English abstract) [闻丞, 顾垒, 王昊, 吕植, 胡若成 (2015) 基于最受关注濒危物种分布的国家级自 然保护区空缺分析. 生物多样性, 23, 591-600.]

Xu HG, Ding H, Ouyang ZY, Zhang WG, Cui P, Xu WH, Liu L, Wu J, Lu XQ, Cao MC, Chen L, Le ZF, Wu Y, Lei JC (2016) Assessing China's progress toward the 2020 Global Biodiversity Targets. Acta Ecologica Sinica, 36, 3847-3858. (in Chinese with English abstract) [徐海根, 丁晖, 欧阳志 云, 张文国, 崔鹏, 徐卫华, 刘立, 吴军, 卢晓强, 曹铭 昌, 陈炼, 乐志芳, 吴翼, 雷军成 (2016) 中国实施2020 年全球生物多样性目标的进展. 生态学报, 36, 3847-3858.]

Yang R (2014) Discussions on nine relationships to build a national park and protected area system in China. Chinese Landscape Architecture, 30(8), 5-8. (in Chinese with English abstract) [杨锐 (2014) 论中国国家公园体制建设 中的九对关系. 中国园林, 30(8), 5-8.]
Yang R (2003) Improving the National Park and Protected Area System of China: Theories and Practice. PhD dissertation, Tsinghua University, Beijing. (in Chinese with English abstract) [杨锐 (2003) 建立完善中国国家公园和保护 区体系的理论与实践研究. 博士学位论文, 清华大学, 北 京.]

Yang R, Cao Y (2018) Discussion on the long term target of protected area coverage in China. Chinese Landscape Architecture, 34(7), 5-12. (in Chinese with English abstract) [杨 锐, 曹越 (2018) 论中国自然保护地的远景规模. 中国园 林, 34(7), 5-12.]

Yang R, Shen XL, Ma KP (2019) Recommendations on building up China's National-park-centric Protected Area System. Biodiversity Science, 27, 137-139. (in Chinese) [杨 锐, 申小莉, 马克平 (2019) 关于贯彻落实“建立以国家 公园为主体的自然保护地体系”的六项建议. 生物多样 性, 27, 137-139.]

Zang CX, Cai L, Li JQ, Wu XP, Li XG, Li JS (2016) Preparation of the China Biodiversity Red List and its significance for biodiversity conservation within China. Biodiversity Science, 24, 610-614. (in Chinese with English abstract) [蔵春金金, 蔡蕾, 李佳琦, 吴晓莆, 李晓光, 李俊生 (2016) 《中国生物多样性红色名录》的制定及其对生物多样性 保护的意义. 生物多样性, 24, 610-614.]

Zhang JY, Zhang YJ (2017) On public participation in the construction of national parks. Biodiversity Science, 25, 80-87. (in Chinese with English abstract) [张婧雅, 张玉钧 (2017) 论国家公园建设的公众参与. 生物多样性, 25, 80-87.]

Zhao ZC, Yang R (2019) On the positioning of protected area planning in National Spatial Planning. Chinese Landscape Architecture, 35(8), 5-11. (in Chinese with English abstract) [赵智联, 杨锐 (2019) 论国土空间规划中自然保护地规 划之定位. 中国园林, 35(8), 5-11.]

Zou YY, Fu YL, Yang LR, Wan XL, Wang Y, Liu JX (2017) China and COP 15: A path for responsible environmental power. Biodiversity Science, 25, 1169-1175. (in Chinese with English abstract) [邹玥屿, 傅钰琳, 杨礼荣, 万夏林, 王也, 刘纪新 (2017) 中国与COP15一一负责任环境大国 的路径选择. 生物多样性, 25, 1169-1175.]

(责任编委：薛达元＼cjkstart责任编辑：黄祥忠) 